\title{
Electrical vibrations in rarefied air without electrodes
}

\section{James Moser}

To cite this article: James Moser (1890) Electrical vibrations in rarefied air without electrodes, Philosophical Magazine Series 5, 29:179, 375-376, DOI: 10.1080/14786449008619952

To link to this article: http://dx.doi.org/10.1080/14786449008619952

曲 Published online: 08 May 2009.

Submit your article to this journal $\pi$

Џll Article views: 2

Q View related articles $\sqsubset$ 
therefore also the self-induction, is independent of the magnetic nature of the substance. In consequence of this, electrical waves of high periods travel in an iron wire with the same velocity as in one of copper. According to an experiment made by Hertz this, as a fact, is the case. Hertz explains this by the assumption that the magnetism of iron cannot follow such rapid vibrations. According to what is here stated the matter is much simpler: the iron remains free from any magnetic action of these vibrations.

From the experiments of $\mathrm{H}$. Hertz, it results that the propagation of electrical waves in thin and thick wires takes place with the same velocity. According to the distribution of such waves on the surface of a conductor, it follows that this velocity in a straight conductor is independent, not only of the magnitude, but also of the form of the section. The coefficient of self-induction may be expressed by twice the potential of the electrical charge on it self divided by the square of the quantity. If in calculating the potential of the current we take the formula propounded by Neumann for the potential of two elements of current, this, in a straight conductor in which only parallel elements occur, reduces to the potential of two elements of the statical charge. If now the current-density as well as that of the charge in the surface are divided according to the same law, the same calculation must be made to determine the two potentials. Both are in like manner dependent on the size and shape of the section; and accordingly the product of the coefficient of induction and the capacity, as well as the velocity of propagation of the waves, are independent of the size and form of the section. The identity in the form of the electrodynamic and electrostatic potential has the consequence that the distribution of the current on such conductors as are parallel, and not connected with each other, may be determined by the rules of electrostatics. Here the potential of a conductor, which is only evoked by the induction of the other, must be called zero.-Wiener Berichte, January 9, 1890.

\section{ELECTRICAI، VIBRATIONS IN RAREFIED AIR WITHOUT ELECTRODES. BY JAMES MOSER.}

Incited by the view of Heaviside and Poynting, that electrical vibrations penetrate into a wire from the surface, and influenced by Hertz's experiments with the wire cage*, the author has used rarefied spaces without electrodes as conductors in which electrical vibrations occur.

A glass tube which contained a gas of constant rarefaction was surrounded with a wider tube, and the rarefaction varied in this by means of the air-pump. The following results were obtained:-

(a) At the ordinary atmospheric pressure in the outer tube the inner tube becomes luminous.

(b) With a sufficient rarefaction of the outer tube the phenomenon is reversed; the inner tube becomes dark and the outer one luminous. Here there is obviously a screening action.

* Wiedemann's Annalen, xxxvii. p. 395. 
In the course of the preceding research the rarefaction was pushed still further, and

(c) The outer tube was again dark, the inner one luminous; so that to the eye this third stage was like the first one.

The more perfect vacuum exerts therefore no screening action; it has lost the power of conducting the electrical current. - Wiener Berichte, January 9, 1880.

ON THE FORMATION OF OYONE BY THE CONTACT OF AIR WITH IGNITED PLATINUM, AND ON THE ELECTRICAL CONDUCTIVITY OF AIR OZONIZED BY PHOSPHORUS. BY PROFS. ELSTER AND GEITEL.

The authors sum up the results of their investigations in the following terms:-

(1) Incandescent surfaces of platinum ozonize the surrounding air, even when combustions are excluded.

(2) When air is ozonized by contact with moist phosphorus it is seen to conduct electricity in the same manner as the gases of flame do.

(3) It could not be found that this process of ozonization had any electromotive force, or that the air which had been subject to it had any unipolar conductivity.

(4) The mere presence of ozone already formed, as well as the production of clouds from ammoniacal salts in the vicinity of phosphorus, are not connected with the origination of the conductivity of the surrounding air, or at any rate only to a subordinate extent. -Wiedemann's Annalen, March 1890.

\section{NOTE IN CONNEXION WITH DROPPING-MERCURY ELECTRODES. BY J. BROWN.}

In the Zeitschrift fir physikalische Chemie, iv. p. 577, there is a reference by Prof. Ostwald to my paper on "Helmholtz's Theory of Mercury-dropping Electrodes," communicated to the Philosophical Magazine for May 1889 by Dr. Lodge, as secretary to the Electrolysis Committee of the British Association.

Prof. Ostwald, however, considers only one of my experiments, viz. that which deals with the current in a wire connecting the dropping mercury with the mercury resting on the bottom of the vessel containing the electrolyte in which the drops form. My experiment shows that this current varies in a direction inverse to the change of resistance of the electrolyte, and is therefore conducted by the electrolyte, and does not consist of charges carried down by the drops as assumed by Helmboltz.

It is perhaps unnecessary to refer to Prof. Ostwald's criticism further than to point out that his method of explaining away my conclusion is inconsistent with the fact brought forward by me, but apparently not considered by Prof. Ostwald, that the current flows just the same whother the drops fall into the resting mercury or not, provided they form in the electrolyte in contact with the resting mercury. 